\title{
Atendimentos Psicossociais a Crianças e Adolescentes Vítimas de Violência Sexual: Percepções de Psicólogas de um Creas/Paefi
}

\author{
Jessica Souza Martins ${ }^{1}$ \\ ${ }^{1}$ Pesquisadora independente.
}

Daniel Kerry dos Santos ${ }^{1}$

${ }^{1}$ Pesquisador independente.

Resumo: Este artigo objetiva problematizar as percepções de psicólogas de um Creas/Paefi da região metropolitana de Florianópolis acerca dos atendimentos psicossociais a crianças e adolescentes em situação de violência sexual. Foram realizadas entrevistas semiestruturadas com três psicólogas que atuam no serviço Paefi de um Creas. A análise das entrevistas está amparada pela perspectiva teórico-metodológica de análise das práticas discursivas e de produção de sentidos, conforme proposta por Spinke Medrado (2004). Elencaram-se as seguintes categorias de análise: a) percepções acerca da violência sexual contra crianças e adolescentes; b) percepções acerca do atendimento psicossocial; e c) percepções acerca da gestão de trabalho e das estratégias de intervenções psicossociais. De modo geral, destaca-se que as percepções sobre violência sexual variam entre leituras complexas e reducionistas; que existem dificuldades em fazer valer o Sistema de Garantia de Direitos de Crianças e Adolescentes e a efetivação de uma gestão de trabalho intersetorial e em rede; que o Estado é ausente e/ou negligente em contextos de vulnerabilidades; que as intervenções centram-se mais nas famílias e nas vítimas e menos nos autores de violência; que, apesar de impasses técnicos, busca-se atuar de acordo com prerrogativas da atuação profissional da psicologia no contexto do Suas. Considera-se que este estudo pode contribuir para a ampliação de problematizações acerca dos atendimentos psicossociais, no contexto do Suas, a crianças e adolescentes vítimas de violência sexual.

Palavras-chave: Violência sexual, Crianças e adolescentes, Atendimento psicossocial, Psicologia, Assistência social.

\section{Psychosocial Assistance to Children and Adolescents Victims of Sexual Violence: Perceptions of Psychologists from a CREAS/PAEFI}

\begin{abstract}
This article aims to problematize the perceptions of psychologists of a CREAS (Specialised Social Aid Reference Centre)/PAEFI (Protection and Specialised Care Services for Families and Individuals) from the Florianópolis metropolitan area on psychosocial care for children and adolescents in situations of sexual violence. We conducted semi-structured interviews with three psychologists working at CREAS/PAEFI service. The analysis of the interviews was supported by the theoretical and methodological framework of the analysis of discursive practices and production of meanings proposed by Spink and Medrado (2004). We listed the following categories of analysis: a) perceptions on sexual violence against children and adolescents; b) perceptions on psychosocial care; and c) perceptions on work management and strategies for psychosocial interventions. In general, we highlighted that perceptions on sexual violence vary between complex and reductionist understandings; that assuring the Rights Guarantee System for Children and Adolescents and making effective the intersectoral and network management of work is difficult; that the State is absent and/or negligent in contexts of vulnerability; that interventions focus more on families and victims and less on perpetrators
\end{abstract}


of violence; that, despite technical impasses, psychologists act according to the prerogatives of professional practices in the context of SUAS (Single Social Welfare System). We consider that this study can contribute to the expansion of problematizations on psychosocial care, in the context of SUAS, to children and adolescents who are victims of sexual violence.

Keywords: Sexual violence, Children and adolescents, Psychosocial assistance, Psychology, Social Assistance.

\title{
Asistencia Psicosocial a Niños y Adolescentes Víctimas de Violencia Sexual: Percepciones de Psicólogas de un Creas/Paefi
}

\begin{abstract}
Resumen: El propósito de este artículo es problematizar las percepciones de psicólogas de un Centro de Referencia Especializado de Asistencia Social del Servicio de Protección y Atención Especializada a Familias e Individuos (Creas/Paefi) de la área metropolitana de Florianópolis (Brasil) sobre la atención psicosocial a niños y adolescentes en situación de violencia sexual. Se realizaron entrevistas semiestructuradas con tres psicólogas que actúan en el servicio Paefi de un Creas. El análisis de las entrevistas se fundamenta en la perspectiva teóricometodológica de análisis de las prácticas discursivas y de producción de sentidos, propuesta por Spink y Medrado (2004). Se enumeraron las siguientes categorías de análisis: 1) percepciones sobre la violencia sexual contra niños, niñas y adolescentes; 2) percepciones sobre la atención psicosocial; y 3) percepciones sobre la gestión del trabajo y estrategias para intervenciones psicosociales. En general, se destaca que las percepciones sobre la violencia sexual varían entre lecturas complejas y reduccionistas; que existen dificultades para hacer cumplir el Sistema de Garantía de los Derechos de la Niñez y la Adolescencia y hacer efectiva la gestión del trabajo intersectorial y en red; que el Estado se encuentra ausente y/o negligente en contextos de vulnerabilidad; que las intervenciones se centran más en las familias y las víctimas, y menos en los perpetradores de violencia; que, a pesar de los impasses técnicos, buscamos actuar de acuerdo con las prerrogativas del ejercicio profesional en psicología en el contexto del Sistema Único de Asistencia Social (Suas). Se espera que este estudio pueda contribuir a la expansión de problematizaciones sobre la atención psicosocial a niños y adolescentes víctimas de violencia sexual, en el contexto del Suas.
\end{abstract}

Palabras clave: Violencia sexual, Niños y adolescentes, Atención psicosocial, Psicología, Asistencia social.

\section{Introdução}

A violência sexual contra crianças e adolescentes é uma violação de direitos humanos e um problema de saúde pública complexo, endêmico e multifacetado (Werneck, Gonçalves, \& Vasconcelos 2014). Além disso, esse tipo de violência pode causar grande impacto no desenvolvimento da vítima e das pessoas envolvidas (Andrade et al., 2011; Veloso, Magalhães, \& Cabral, 2017). De acordo com as políticas públicas de Assistência Social preconizadas pelo Sistema Único de Assistência Social (Suas), a unidade pública responsável pelo atendimento a crianças e adolescentes vítimas de violência sexual é o Centro de Referência Especializado de Assistência Social (Creas), por meio do serviço de Proteção e Atendimento Especializado a Famílias e Indivíduos (Paefi).

Neste artigo, apresentamos os resultados de uma pesquisa que se dedicou a problematizar a atuação da psicologia no contexto do Creas/Paefi frente a situações de violência sexual contra crianças e adolescentes. Considerando a relevância de difusões de reflexões acerca do tema em questão, elencamos como objetivo geral da pesquisa problematizar as percepções de psicólogas de um Creas/Paefi da região 
metropolitana de Florianópolis sobre atendimentos psicossociais a crianças e adolescentes vítimas de violência sexual. Como objetivos específicos buscou-se: a) identificar as percepções de psicólogas quanto às ações desenvolvidas pela equipe no atendimento a crianças e adolescentes vítimas de violência sexual; b) identificar as dificuldades encontradas por psicólogas para o atendimento de crianças e adolescentes vítimas de violência sexual; e c) identificar as estratégias utilizadas por psicólogas para o atendimento de crianças e adolescentes vítimas de violência sexual.

\section{Violência sexual contra crianças e adolescentes}

Em linhas gerais, podemos classificar as violências contra crianças e adolescentes a partir dos contextos nos quais ocorrem: intrafamiliar, quando existe um laço familiar, biológico ou não; e extrafamiliar, quando o autor da violência não tem laços familiares ou de responsabilidade com a vítima (Conselho Federal de Psicologia [CFP], 2009). Além da classificação contextual, de acordo com Veloso et al. (2017), as violências também podem ser classificadas por modalidades e/ou tipos, como: negligência, violência psicológica, violência física e violência sexual.

De acordo com o CFP (2009), a violência sexual contra crianças e adolescentes ocorre em todas as classes sociais. As violências, em suas diversas expressões, podem também atingir todas as faixas etárias, dentro e fora do ambiente familiar (Paixão \& Deslandes, 2010; Werneck et al., 2014). Segundo o CFP (2009, p. 29), identificar as causas dos casos das violências dirigidas contra crianças e adolescentes é um trabalho complexo, pois trata-se de fenômenos interrelacionados que envolvem fatores de diversas ordens: individuais, sociais, culturais, familiares, psicológicos e econômicos.

Conforme a Lei n. 13.431, de 4 de abril de 2017, que "estabelece o sistema de garantia de direitos da criança e do adolescente vítima ou testemunha de violência e altera a Lei no ${ }^{\circ} .069$, de 13 de julho de 1990 (Estatuto da Criança e do Adolescente)", a violência sexual contra crianças e adolescentes é entendida como "qualquer conduta que constranja a criança ou o adolescente a praticar ou presenciar conjunção carnal ou qualquer outro ato libidinoso, inclusive exposição do corpo em foto ou vídeo por meio eletrônico ou não". Ainda de acordo com essa lei, o conceito de violência sexual pode compreender uma ou mais das seguintes especificidades a) abuso sexual; b) exploração sexual comercial; c) tráfico de pessoas com fim de exploração sexual (Lei n. 13.431, 2017).

Dentre os tipos de violência contra crianças e adolescentes, a mais impactante é a violência sexual (CFP, 2009). Embora reconhecida como um fenômeno antigo, a violência sexual só foi considerada um problema social a partir do século $\mathrm{XX}$, quando passou a ser concebida como uma das formas de violação dos direitos humanos que pode comprometer seriamente o desenvolvimento físico, psicológico e social das vítimas (CFP, 2009). Segundo o CFP (2009, p. 40), os efeitos da violência variam de acordo com o tipo e grau de violência, a duração de exposição à situação, a idade da criança e/ou do(a) adolescente, a diferença de idade entre o autor da agressão e a vítima, a importância da relação entre o autor da agressão e a vítima, a ausência de figuras parentais protetoras e de apoio social, e o grau de segredo e de ameaças contra a criança ou adolescente.

Conforme apontado no Mapa da Violência contra Crianças e Adolescentes de 2012 (Waiselfisz, 2012), de acordo com os registros do Sistema de Informação de Agravos de Notificação (Sinan), em 2011 foram atendidas, no Sistema Único de Saúde (SUS), 10.425 crianças e adolescentes vítimas de violência sexual, majoritariamente $(83,2 \%)$ do sexo feminino, com prevalência etária entre 10 e 14 anos. Já no Mapa da Violência de 2015 (Waiselfisz, 2015), a violência sexual aparece em terceiro lugar como o tipo de violência mais notificada pelo Sinan, somando "11,9\% dos atendimentos, com maior incidência entre as crianças até 11 anos de idade (29,0\% dos atendimentos) e as adolescentes $(24,3 \%)$ " (Waiselfisz, 2015, p. 50). Importante destacar, no entanto, que, frente a essas estatísticas, devese atentar para os riscos das subnotificações:

Tem que ser considerado que os quantitativos registrados pelo SINAN representam só a ponta do iceberg das violências cotidianas que efetivamente acontecem: as que demandam atendimento do SUS e que, paralelamente, são declaradas como violência. Por baixo desse quantitativo visível, um enorme número de violências cotidianas nunca chega à luz pública (Waiselfisz, 2012 p. 62).

A Lei n. 8.069, de 13 de julho de 1990, que instituiu o Estatuto da Criança e do Adolescente (ECA), dispõe sobre a proteção integral às crianças e às(aos) 
adolescentes estabelecendo que eles(as) são considerados(as) sujeitos de direitos que vivenciam condições especiais e particulares, cujo desenvolvimento físico, mental e social deve ser garantido em condições de liberdade e de dignidade. O ECA preconiza que é dever de todos os cidadãos comunicar os casos de violência, negligência, exploração, discriminação, crueldade e opressão, além de prever, em seu art. 245, penalidades para profissionais da saúde e instituições que deixarem de comunicar as ocorrências, sejam elas confirmadas ou suspeitas (Lei n. 8.069, 1990). A aplicação dessa lei foi uma das conquistas mais importantes para a sociedade e para as crianças e adolescentes vítimas de violência. No entanto, para as violências contra esse grupo populacional serem superadas, urge não "apenas" a aprovação de leis e normas, mas um complexo e intricado processo de transformações estruturais, sociais, históricas e culturais (Silva, Lunardi, Ribeiro, Oliveira, \&Vasquez, 2014). Dentre os dispositivos públicos disponíveis para esse tipo de transformação e para a efetivação das leis de proteção integral às crianças e adolescentes, encontra-se o Suas e seus equipamentos.

\section{O Suas e seus equipamentos: possibilidades de atenção socioassistencial a crianças e adolescentes vítimas de violência sexual}

O Suas foi criado a partir da Política de Assistência Social e se organiza em duas grandes estruturas articuladas entre si: a Proteção Social Básica (PSB) e a Proteção Social Especial (PSE) (CFP, 2012). De acordo com a Política Nacional de Assistência Social (Ministério do Desenvolvimento Social e Combate à Fome [MDS], 2004), a PSB objetiva prevenir situações de risco por meio do desenvolvimento de potencialidades e do fortalecimento de vínculos familiares e comunitários. O público prioritário da PSB é a população que vive em situação de vulnerabilidade social decorrente da pobreza e da privação e fragilização de vínculos afetivos. Os Centros de Referência da Assistência Social (Cras) são os equipamentos que têm como função realizar o acolhimento desses indivíduos e de suas famílias (CFP, 2009).

Já a PSE, de acordo com a Política Nacional de Assistência Social (MDS, 2004), define-se como:

...uma modalidade de atendimento assistencial destinada a famílias e indivíduos que se encon- tram em situação de risco pessoal e social, por ocorrência de abandono, maus tratos físicos e/ ou psíquicos, abuso sexual, uso de substâncias psicoativas, cumprimento de medidas socioeducativas, situação de rua, situação de trabalho infantil, entre outras (MDS, 2004, p. 37).

Nesse sentido, a PSE destina-se a casos notadamente complexos e que impliquem violações de direitos. Os serviços de PSE estão vinculados ao Sistema de Garantia de Direitos (SGD) e se articulam com o Poder Judiciário, o Ministério Público, os Conselhos Tutelares e outros órgãos e ações do Executivo (CFP, 2012).

A PSE deve ser organizada para acolher e atender situações de maior complexidade. Por isso, demanda intervenções especializadas e específicas. Nesse sentido, os serviços e ações são organizados em dois níveis: alta complexidade, quando os indivíduos e famílias estão afastados do convívio familiar e exige-se intervenção que garanta a proteção integral; e média complexidade, quando os vínculos familiares e comunitários não foram rompidos (CFP, 2009). Os serviços, programas e ações de média complexidade devem ser coordenados pelos Creas, equipamento do SUAS sobre o qual esse artigo se foca.

Considerando a definição expressa na Lei n. 12.435 (2011), o Creas é uma Unidade Pública Estatal, de prestação de serviços especializados e continuados, de abrangência municipal ou regional, que tem como papel ofertar serviços a indivíduos e famílias que tiveram seus direitos violados em decorrência de abandono, negligência, maus-tratos, ameaças, violações físicas, psíquicas, abuso e exploração sexual e demais violações. Dada a complexidade das situações atendidas no Creas, a equipe deverá ter qualificação técnica e reunir um conjunto de conhecimentos e habilidades que sejam compatíveis com a natureza e os objetivos dos serviços ofertados (CFP, 2009).

O dispositivo do Creas responsável pelo atendimento a crianças e adolescentes vítimas de violência sexual é o serviço de Paefi. Conforme a Tipificação Nacional dos Serviços Socioassistenciais, o Paefi é o serviço de apoio, orientação e acompanhamento a famílias em situação de ameaça ou violação de direitos. Assim, cabe ao Paefi oferecer acolhimento, escuta qualificada, atendimento multiprofissional, psicossocial e jurídico, acompanhamento individual e grupal e atividades que promovam a construção de projetos pessoais e sociais por meio de ações e de atividades 
psicoeducativas que visem à promoção da superação da situação de violência (Romeu, Elias, \& Silva, 2014). $\mathrm{O}$ atendimento psicossocial é de competência dos(as) psicólogos(as) e dos(as) assistentes sociais; a orientação e o apoio jurídico ficam a cargo dos(as) advogados(as). No entanto, mesmo que cada profissional tenha sua atribuição, o atendimento psicossocial deve ser realizado de forma integrada ao acompanhamento jurídico, de modo que cada uma das áreas possa fornecer subsídios uma para a outra (Romeu et al., 2014).

Idealmente, o trabalho desenvolvido por psicó$\operatorname{logos}($ as) e assistentes sociais deve estar pautado na perspectiva do atendimento psicossocial (CFP, 2009; Romeu et al., 2014). Este tipo de atendimento foca nas famílias, observando seus contextos culturais e socioeconômicos. As ações planejadas devem ser articuladas de acordo com um plano de atendimento que envolva as demais políticas públicas, visando, assim, consolidar uma rede de proteção integral. De acordo com Romeu et al. (2014), o atendimento psicossocial é realizado em algumas etapas: acolhimento e triagem, elaboração do plano de atendimento, encaminhamentos, acompanhamento e encerramento do atendimento.

Considerando a gravidade dos casos de violação de direitos contra crianças e adolescentes que se presentificam no Paefi, esse serviço deve apresentar uma proposta ética que perpassa a gestão da política, as condições e a infraestrutura para os atendimentos, os fluxos dos encaminhamentos e os retornos do atendimento, a qualificação e a atualização continuada dos profissionais (Romeu et al., 2014). Buscando conhecer melhor os desafios da atuação profissional da psicologia no âmbito das Políticas Públicas de Assistência Social, especialmente do Creas/Paefi, este artigo apresenta os resultados de uma pesquisa que objetivou responder a seguinte questão: quais são as percepções de psicólogas de um Creas/Paefi da região metropolitana de Florianópolis sobre atendimentos psicossociais a crianças e adolescentes vítimas de violência sexual?

\section{Metodologia}

\section{Delineamentos e participantes}

No que se refere ao objetivo, trata-se de uma pesquisa exploratória, que, segundo Gil (2002 p. 41), tem como objetivo "proporcionar maior familiaridade com o problema, com vistas a torná-lo mais explícito ou a constituir hipóteses". Quanto à natureza, a pesquisa classifica-se como qualitativa. De acordo com Denzin e Lincoln (2006), a pesquisa qualitativa envolve uma abordagem interpretativa, buscando entender os fenômenos em termos dos significados que as pessoas a eles atribuem. O corte deste estudo é transversal, ou seja, a pesquisa foi realizada em um curto período.

Participaram desta pesquisa três psicólogas ${ }^{1}$ Camila, Carmem e Helena ${ }^{2}$ - que atuavam há, no mínimo, três meses no Paefi de um Creas localizado na região metropolitana de Florianópolis (Santa Catarina). Foram selecionadas participantes que tivessem alguma experiência profissional no atendimento a crianças e adolescentes vítimas de violência sexual. As interlocutoras da pesquisa tinham entre 25 e 55 anos de idade e se autodeclararam de raça branca e do gênero feminino. No que se refere ao tempo de formação em psicologia, este variou entre 3 e 16 anos. Todas as entrevistadas relataram ter concluído ao menos uma especialização, entre elas: recursos humanos, gestão de pessoas, arteterapia, psicopedagogia e psicologia social. Em relação aos aspectos laborais, o tempo médio no serviço do Paefi variou entre 3 meses e 4 anos.

O contato inicial com as participantes foi realizado presencialmente, quando se pôde apresentar as intenções e os objetivos da pesquisa, bem como convidar formalmente as profissionais para a participação do estudo e esclarecer os procedimentos metodológicos e os critérios éticos da pesquisa.

\section{Procedimentos e instrumentos}

A escuta das narrativas aconteceu em entrevistas individuais e semiestruturadas, que visavam possibilitar que a participante discorresse sobre o tema proposto. A entrevista foi organizada considerando os seguintes eixos temáticos: a) dados de identificação da participante; b) aspectos referentes às percepções sobre atendimentos psicossociais a crianças e adolescentes em situação de violência sexual; e c) aspectos referentes ao cotidiano de trabalho em casos de violência sexual contra crianças e adolescentes. O tempo de duração das entrevistas foi, em média, de uma hora.

\footnotetext{
${ }^{1}$ Inicialmente pretendia-se entrevistar quatro psicólogos(as). Porém, participaram desta pesquisa apenas três psicólogas, pois esse era o número de profissionais de psicologia atuantes no serviço.

${ }^{2}$ Para preservar o sigilo, os nomes utilizados são fictícios.
} 
Os locais onde as entrevistas ocorreram foram definidos entre as partes (pesquisadora entrevistadora e participantes). No contato realizado para o agendamento da entrevista, optou-se por realizá-la no próprio Creas, uma vez que aquele ambiente, além de ser acessível para as participantes, garantia as condições necessárias referentes às questões éticas e à garantia do sigilo das informações.

Após a realização de todas as entrevistas, deu-se prosseguimento à organização e análise das narrativas. Primeiramente, realizou-se a transcrição das entrevistas. Em seguida, foram construídas categorias gerais, de natureza temática, que atendessem aos objetivos da pesquisa. Organizaram-se os conteúdos, procurando observar os processos de interanimação dialógica a partir da esquematização visual da entrevista e, por fim, analisar os sentidos comunicados e expressados nas narrativas. A análise das entrevistas foi realizada tendo como referência teórico-metodológica a análise das práticas discursivas e de produção de sentidos, conforme proposta por Spink e Medrado (2004). Nessa perspectiva, define-se práticas discursivas "como linguagem em ação, ou seja, as maneiras a partir das quais as pessoas produzem sentidos e se posicionam em relações sociais cotidianas" (Spink \& Medrado, 2004, p. 26). A produção de sentidos é um modo de entender a construção social dos conceitos utilizados no cotidiano para dar sentido ao mundo, portanto, não é uma atividade cognitiva intraindividual, mas uma prática social e dialógica (Spink \& Medrado, 2004). Frente a essa perspectiva teórico-metodológica, enfatizamos que os relatos escutados não dizem respeito a verdades acabadas e definitivas, mas expressam narrativas, saberes e conhecimentos situados e contingentes que se esboçam no cotidiano das práticas, no fazer do dia a dia, nas dinâmicas institucionais e nas realidades macro e micropolíticas.

\section{Aspectos éticos}

No contexto da entrevista, solicitou-se que a participante lesse o Termo de Consentimento Livre e Esclarecido (TCLE), já aprovado pelo Comitê de Ética em Pesquisa da Universidade do Sul de Santa Catarina. Antes do início da entrevista e após a leitura e concordância do TCLE, ele foi preenchido e assinado pela participante, pesquisadora e pesquisador responsável. No TCLE constaram as explicações a respeito dos objetivos da pesquisa; a autorização de gravação de voz da entrevista; os direitos das participantes; e os riscos e benefícios.

\section{Resultados e discussão}

\section{Percepções acerca da violência sexual contra crianças e adolescentes}

A violência sexual contra crianças e adolescentes é um problema de saúde pública e de violação de direitos que nos impele a problematizar concepções de infância, adolescência, sexualidade, gênero, entre outras questões estruturais que constituem a ordem social hegemônica no Brasil (CFP, 2009). Nesse sentido, mesmo que se esteja diante de um sujeito ou de grupo familiar, não se pode perder de vista que a violência é um fenômeno complexo, multicausal, multifatorial e multidimensional (CFP, 2020).

No que se refere à dimensão psicossocial das crianças e adolescentes vítimas de violência sexual atendidas no Creas/Paefi onde a pesquisa foi realizada, Carmem, Camila e Helena relataram que comumente atendem crianças e adolescentes de camadas populares. Compreendemos que o acesso mais frequente por essa população tenha relação com o fato de que, em geral, as camadas médias/altas não costumam acessar as políticas públicas de Assistência Social. Esse dado invisibilizaria as violências que ocorrem entre as camadas sociais mais privilegiadas. Já entre as camadas mais populares, que tendem a compor o grupo populacional atendido pelo Creas, os contextos de vulnerabilidades sociais ficam mais evidentes, conforme relataram as entrevistas.

A violência sexual contra crianças e adolescentes, de acordo com as psicólogas Camila e Helena, respectivamente, foi significada como um fenômeno situado em contextos locais e familiares:

A gente observa, principalmente ali na comunidade, que é uma coisa meio velada, assim, meio cultural...Quando a gente chega para fazer o atendimento, várias pessoas da família já sofreram isso. Às vezes a mãe observa algumas coisas, mas já sofreu também, então acaba abafando. Principalmente neste serviço, aqui eu observo que a vulnerabilidade dessas famílias, a questão cultural favorece muito a violência sexual (Camila).

...eu penso que violência sexual está muito relacionada a experiências anteriores, o aprendizado... como essas pessoas aprenderam a lidar, a viver com a sexualidade. E aí aprenderam dessa forma, para 
muitos deles é uma forma de afeto, né?...eu ouvi situações de crianças de 8 anos estarem sendo suspeitas de cometerabusos com irmãos mais novos. Sãofamílias nas quais a sexualidade não é algo que se torna privado, principalmente em comunidades onde as condições de moradia não proporcionam essa privacidade. Então, era comum você atender famílias que traziam relatos de reclamação por crianças estarem representando, estarem tendo comportamento sexualizado ou repetindo...eu lembro de situações em que o pai falava que as crianças reclamavam porque o pai não fazia com eles também o que faziam com a mãe...eles cobravam, eles reclamavam. E aí qual a concepção que eles tinham de violência, né? ...semana passada nos chegou uma família na qual o suposto violador é o tio de uma criança de 5 anos, mas eles residem todos na mesma residência, só que ele tem 14 anos e ela tem $5 . . .($ Helena).

De acordo com Camila e Helena, a violência sexual faz parte de um contexto socioeconômico e cultural que pode influenciar o comportamento dos familiares e dos autores de violência. No entanto, cabe questionar: o que significa atribuir a causalidade de um fenômeno recorrente em todas as classes sociais a um contexto socioeconômico e cultural específico? Quais os riscos desse tipo de generalização, que atribui uma correlação direta entre "meio cultural" (entendido aqui como os territórios de camadas populares) e "violência sexual"? Observa-se que as explicações dadas sobre violência sexual tendem, por vezes, a reduzir o fenômeno da violência aos sistemas familiares e/ou ao meio no qual as pessoas vivem. Nos relatos de Helena e Camila, observamos, por vezes, uma espécie de determinismo cultural e socioeconômico que supostamente explicaria as causas da violência sexual. Carmem, por sua vez, também destaca a situação socioeconômica como um dos fatores de exposição à violência sexual (que estaria relacionada com outras situações de vulnerabilidades a que estão submetidas as famílias). No entanto, ao mesmo tempo em que relaciona "violência contra crianças e adolescentes" à "situação socioeconômica das famílias", enfatiza que a questão da violência também está presente em outras camadas sociais:

Muitas vezes a situação socioeconômica é uma das características sim, como eu disse, do nosso público. E são crianças, famílias que estão pas- sando por fragilidades, pelo fato da própria violência. E às vezes a violência já vem devido a outras fragilidades da família, seja de estrutura familiar, econômica... então a realidade é bem diversificada, apesar de que...existe uma característica socioeconômica que vai de famílias de extrema vulnerabilidade social, no sentido de extrema pobreza, até famílias que não necessariamente tem uma situação socioeconômica tão desprivilegiada (Carmem).

As interlocutoras evocaram, como formas explicativas às causas da violência sexual, situações de coabitação (realidade de muitas famílias brasileiras de camadas populares que não explica, necessariamente, a violência sexual, haja vista que esse tipo de violência também acontece com frequência em outras classes sociais (CFP, 2012)); noções enviesadas por uma certa perspectiva de classe social acerca da presença ou ausência de privacidade e de concepções de vida privada; essencialismos sobre classe social e sexualidade (a ideia de que camadas populares não puderam "aprender" suficientemente sobre como lidar com as questões de sexualidade e que, portanto, a sexualidade não estaria resguardada pela "sacralidade" do mundo privado e por certa moral sexual); apelo à ideologia familista, que direciona o olhar para uma concepção de família supostamente natural, a-histórica e descolada de outras instituições e estruturas de poder; reprodução da famigerada ideia de "família desestruturada" ou "sem estrutura", concepção que, aliançada à ideologia familista, pressupõe um ideal de normalidade psicológica e moral às famílias; ausência de reflexões sobre a questão da educação sexual nas escolas (marcando, de modo implícito, a ideia de responsabilidade exclusiva da família em abordar e trabalhar questões de sexualidade, incluindo a violência sexual); naturalização acrítica da violência como forma de "afeto" nas camadas populares; ausência de reflexão sobre gênero e sexualidade como categorias de análise das relações sociais e familiares e como relação de poder que incide nas realidades psicossociais; etc.

A partir das entrevistas, identificou-se que a violência sexual praticada contra crianças e adolescentes atendidas naquele Creas/Paefi ocorre, com maior frequência, no interior das famílias e tem como principais autores da violência o pai, o padrasto, o tio, o avô ou o irmão. Essa constatação acerca dos autores da violência está em consonância com os dados 
apresentados no Mapa da Violência Contra Crianças e Adolescentes de 2012 (Waiselfisz, 2012). Carmem, ao relatar sua percepção sobre os autores de violência sexual praticada contra crianças e adolescentes, afirmou: “...existem diferentes autores da violência, podem ser outras crianças, podem ser adolescentes, podem ser adultos, podem ser mulheres, podem ser homens, pode ser um grupo de pessoas contra uma pessoa". Apesar de expressar a percepção de que a violência pode ser praticada por diversos autores, Carmem não se aprofundou nesse tema específico, restringindo seu relato a uma concepção mais genérica e descritiva sobre violência sexual sem, com isso, apontar para as especificidades que podem permear as relações entre vítima(s) e autor(es) da violência. Ressalta-se que, na maioria dos casos, as vítimas de violência sexual também são vítimas de outras formas de violência. Segundo Pedersen (2010), as desigualdades de gênero, o machismo, o patriarcado e as relações de poder são características que historicamente marcaram e ainda marcam as famílias e as violências reproduzidas em seu interior.

Muitos dos discursos presentes nos relatos apontam para a violência sexual como um problema cuja causa estaria localizada nas "famílias" ou no "ambiente" (definido ora como o espaço físico onde as pessoas vivem, ora como meio cultural compartilhado). Tais discursividades acionadas para explicar a violência sexual parecem se distanciar de debates que visam analisar e compreender esse fenômeno como algo constituído por diversos imbricamentos complexos e por questões de ordem política, estrutural e de poder. O risco de explicações desse tipo reside no fato de que ao responsabilizar e culpabilizar apenas as famílias e os locais onde vivem, desresponsabiliza-se, assim, o Estado e a sociedade como esferas corresponsáveis em assegurar os direitos de crianças e adolescentes, tal como previsto no ECA. De acordo com Pereira e Guareschi (2017), a lógica de culpabilizar as famílias reforçaria a racionalidade de que outras esferas da sociedade não teriam relação com o que se passa nos contextos familiares. Para os autores, é comum, em políticas de Assistência Social, a presença de discursos que definem as famílias em situações de vulnerabilidades como "disfuncionais", "incapazes", "doentes" ou "anormais". Tais designações tratam as famílias como culpadas por supostas falhas em assegurar o cuidado e a proteção aos seus membros.
No entanto, em face a esse tipo de retórica, perde-se de vista que o próprio Estado não ofereceu e não oferece condições básicas mínimas de existência para essas famílias. Segundo Pereira e Guareschi (2017), ocorre, nesses casos, uma "transferência de responsabilidade do Estado para a sociedade civil e as famílias", o que reforçaria a "ideologia de que as famílias, independentemente de suas condições de vida, devem ser capazes de proteger os seus membros" (Pereira \& Guareschi, 2017, p. 10).

Se por um lado sabemos que a maior parte dos casos de violência sexual acontece em contextos intrafamiliares (Waiselfisz, 2012), por outro lado temos que nos perguntar de que modo, então, é possível atuar junto às famílias e, ao mesmo tempo, responsabilizar e implicar outras esferas - da sociedade civil e do poder público - no que diz respeito às redes de proteção e atendimento e às políticas públicas de prevenção à violência. Nesse sentido, é fundamental afirmarmos a importância de políticas públicas que abordem temas como educação em gênero e sexualidades, saúde sexual e reprodutiva, violência contra crianças e adolescentes, direitos humanos, entre outros. Essas problemáticas evidenciam que a vida privada é inextricável à vida pública e política, ou seja, que o "pessoal é político", expressão que feministas utilizam há décadas para enfatizar que o que acontece na vida privada (ou seja, no interior das famílias) está intimamente enredado em contextos históricos e sociopolíticos. De acordo com Itaboraí (2017, p. 33) “...as famílias não são ilhas fechadas sobre si mesmas, mas são afetadas pelos contextos sociais".

Em alguns relatos, observamos uma compreensão mais complexa acerca do contexto psicossocial em que as psicólogas atuam. Algumas das entrevistadas destacaram a negligência do Estado, a precarização e/ou ausência das políticas públicas, a exclusão e a violação de direitos e os contextos estruturais da vulnerabilidade social das famílias - estes entendidos não como meros "desequilíbrios individuais ou familiares", mas como resultantes de projetos históricos e políticos que mantêm certos grupos sociais em condições precárias de existência. Nessa perspectiva, Helena relata:

Geralmente são famílias nas quais a maioria a mãe é responsável pelo sustento, pela educação, numa realidade que tem pouco ou nenhuma estrutura em termos de políticas públicas. Tem 
uma unidade pública de saúde que não comporta a população, escolas que também não possuem vagas disponíveis a todos, projetos no contraturno que seria o serviço de convivência também não tem, então é uma população que vem de uma realidade, em Estado de exceção mesmo, uma população que eu diria que vive à margem...às vezes isso desmotiva um pouco, que você sabe que essas mães geralmente são responsabilizadas porque o filho não está na escola, mas as políticas públicas onde estão para garantir o acesso à escola, o acesso ao projeto no contraturno, ou educação infantil? Educação infantil é lamentável sabe?...A gente trabalha a violação de direitos por parte da família, mas a gente sabe que por parte do Estado, em muitas situações, é onde existe a maior violação, e aí muitas situações a gente não dá conta, nosso maior problema! (Helena).

De modo geral, pareceu-nos que as entrevistadas, ao falarem sobre violência sexual e as condições de vida das pessoas atendidas no serviço, apresentavam percepções que intercalavam compreensões mais complexas acerca das desigualdades sociais e estruturais e leituras genéricas e calcadas nas próprias vivências imediatas testemunhadas em seus cotidianos de trabalho. O conhecimento empírico construído com base naquilo que se observa no trabalho é fundamental, mas percebemos, a partir dos relatos, pouca articulação com reflexões teóricas que pudessem subsidiar e complexificar análises mais críticas sobre os fenômenos com os quais se atua. Sabe-se, a partir de orientações técnicas para atuação profissional do(a) psicóloga no Suas (CFP, 2009, 2012, 2020), que, em razão da complexidade das situações atendidas em equipamentos como o Creas/Paefi, o(a) profissional deve reunir um conjunto de conhecimentos teóricos compatíveis com as especificidades e singularidades dos fenômenos das violências. De acordo com o CFP (2012), é crucial que, no contexto do trabalho nas políticas públicas, psicólogos(as) contextualizem as teorias psicológicas e suas respectivas metodologias. Assim, o diálogo com áreas e teorias afins à psicologia se faz urgente para que não se reproduzam práticas e leituras que deixem escapar as complexidades das realidades psicossociais e para que não se naturalizem instituições, dispositivos e fenômenos tão presentes nesse campo de atuação.

\section{Percepções acerca do atendimento psicossocial}

Identificou-se que as entrevistadas entendem que, em casos de violência sexual contra crianças e adolescentes, a articulação com a rede intersetorial é parte integrante do atendimento psicossocial prestado no Creas/Paefi. Conforme relata Carmem:

...o nosso trabalho é de orientação, apoio, acolhimento a família, a essa criança, de procurar também dar novos significados ao que ocorreu.... É um assunto delicado e é um assunto com que não dá para se atender apenas pelo PAEFI. Então o nosso trabalho também é de articulação de rede (Carmem).

Segundo os relatos, os casos de violência sexual contra crianças e adolescentes são considerados prioridade máxima, devido à condição peculiar de desenvolvimento das vítimas. As entrevistadas reconhecem e tentam fazer valer o princípio da prioridade absoluta do direito de crianças e adolescentes, tal como preconizado no ECA. Naquele contexto, parece haver a compreensão de que o papel de psicólogos(as) na Assistência Social também é atuar como mediadores(as) e articuladores(as) dos serviços em que atuam com outras políticas públicas, fazendo valer, assim, o SGD, do qual o Creas é um equipamento integrante. De acordo com o CFP (2012), o trabalho nos Creas deve ser interdisciplinar, intersetorial e interinstitucional e os(as) profissionais de psicologia devem atuar no sentido de otimizar essa perspectiva de trabalho e de fluxos de atendimentos.

Helena relatou que, durante os atendimentos psicossociais, também é possível realizar um trabalho voltado para a orientação e conscientização acerca da problemática da violência sexual:

Eu percebo o atendimento aqui relacionado à orientação mesmo, à orientação e ao ensinamento sobre o que é violência. Na maioria das vezes, elas [as famílias] não sabem, não têm noção de que estão sendo vítimas de uma violência; ou, quando têm noção do que é violência, eles [os membros da família] não se percebem empoderados para acabar com aquela violência. É como se fosse "aquilo mesmo" $e$ eles não pudessem mudar. Então, o trabalho do Paefi é conscientizar que isso é uma violência e eu tenho o direito de não deixar isso acontecer (Helena). 
Observou-se, nos relatos, a compreensão de que $\mathrm{o}$ atendimento e o acompanhamento psicossocial em casos de violência sexual demanda uma articulação com a rede das políticas públicas e um trabalho direto com as famílias (que pode viabilizar a construção de vínculos com o serviço), bem como reflexões e discussões acerca das singularidades dos fenômenos que se apresentam no equipamento. Esse fazer é complexo, uma vez que impõe a necessidade de atenção direta aos(às) envolvidos(as) nas violações de direitos e uma boa compreensão acerca da gestão de trabalho intersetorial e interdisciplinar, não apenas na Assistência Social, como em outras políticas públicas que integram a rede de proteção às crianças e aos adolescentes.

De acordo com as orientações técnicas em relação à atuação nos Creas (MDS, 2011), o estudo e o trabalho intersetorial potencializam a capacidade de os(as) profissionais responderem às demandas complexas. Nesse sentido, o princípio da intersetorialidade e da incompletude institucional deve estar presente em todas as ações dos Creas na lida com indivíduos e famílias que estejam passando por violações de direitos e situações de vulnerabilidades. Apesar dessas prerrogativas, na percepção das psicólogas, a "rede do município está desarticulada", o que suscita dificuldades tanto no trabalho cotidiano, quanto na resolução dos casos apresentados. As três psicólogas relataram suas dificuldades acerca da efetivação de um trabalho em rede:

...é um atendimento bem complexo, não é integral né, a gente não consegue fazer os encaminhamentos que seriam efetivos para aquele caso. A principal dificuldade é isso, é a rede (Camila).

Eu acho que a maior dificuldade, às vezes, é você perceber uma necessidade, mas você não ter como efetivar o encaminhamento, por exemplo, saúde mental do município é bem difícil né, é complicado (Helena).

Nem sempre os outros órgãos competentes estão articulados, ou fazendo o que a gente pensa que poderia (Carmem).

A articulação de uma rede de proteção à infância e adolescência (Saúde, Assistência social, Educação, Segurança pública e Sistema de Justiça) é algo que teoricamente deveria estar no horizonte dos(as) profissionais, caso a gestão de trabalho estivesse funcionando de acordo com o princípio da intersetorialidade. Toda essa articulação se justifica, uma vez que:

ações isoladas são insuficientes para prevenir o abuso, para responsabilizar o autor de violência sexual, para atender às vítimas ou para apoiar as famílias a fim de evitar reincidências. São essenciais, portanto, as articulações em rede dos serviços já existentes, a criação de redes territoriais de proteção que possam acompanhar a qualidade do atendimento de crianças e de adolescentes vítimas de abuso ou de exploração sexual e também manter um controle social sobre a responsabilidade do Sistema de Garantia dos Direitos (Santos, Ippolito, \& Magalhães, 2014, p. 125).

Apesar das prerrogativas do trabalho intersetorial, escutamos das entrevistadas que o funcionamento da rede está longe do que preconizam os documentos técnicos de atuação nos Creas, como as cartilhas elaboradas pelo CFP/Crepop (CFP, 2009, 2012, 2020). De acordo com as cartilhas, a rede deve estar articulada e operar na referência e contrarreferência com os demais serviços socioassistenciais e demais políticas públicas (CFP, 2012). Para Pedersen ${ }^{3}$ (2008 apud Faraj \& Siqueira, 2012 p. 78), uma rede efetiva não representa um conjunto de profissionais e instituições que atuam isoladamente, mas sim profissionais e instituições que se reconheçam, "tendo consciência da finalidade e do papel de cada instituição, para que o trabalho ocorra de forma horizontal e descentralizada, a fim de maior qualidade de informações e encaminhamentos".

Outra questão apontada pelas entrevistadas em relação aos atendimentos psicossociais refere-se à problemática da revitimização de crianças, adolescentes e suas famílias vítimas de violência sexual. De acordo com o Decreto n. 9.603 (2018, art. 5º), revitimização é definida como:

Discurso ou prática institucional que submeta crianças e adolescentes a procedimentos desne-

\footnotetext{
${ }^{3}$ Pedersen, J. R. (2008). Serviço de enfrentamento à violência, abuso e exploração sexual contra crianças e adolescentes: a busca pela garantia dos direitos da população infanto-juvenil. In L. M. Mendes \& N. A. Marcheza (Orgs.), Expressão de violência e seu enfrentamento no CREAS/Centro de Referência Especializado da Assistência Social (pp. 19-37). Méritos.
} 
cessários, repetitivos, invasivos, que levem as vítimas ou testemunhas a reviver a situação de violência ou outras situações que gerem sofrimento, estigmatização ou exposição de sua imagem.

Por mais que os(as) profissionais que atuam nos equipamentos socioassistenciais lutem contra obstáculos e dificuldades durante os atendimentos e tentem contribuir para efetivar as medidas de proteção, muitas vezes esses serviços também podem produzir a revitimização de crianças e adolescentes envolvidos(as) em situação de violência sexual. A revitimização pode acontecer tanto pela repetição de ações (por exemplo, diversas entrevistas, realizadas no mesmo serviço e/ou em outros dispositivos da rede, que perguntam sempre as mesmas coisas), como pela descontinuidade do acompanhamento, pela demora no atendimento ou mesmo pela mudança do Creas de referência. Carmem comentou a esse respeito:

...agora com dois Creas, às vezes a família muda de um Creas para o outro, então tem várias situações que faz com que às vezes uma família passe por várias equipes técnicas, isso também vai prejudicando de certa forma o atendimento a essa família (Carmem).

Deste modo, a revitimização ocorre todas as vezes em que as crianças, adolescentes e suas famílias ficam emocionalmente expostos ao recontarem suas histórias. De acordo com Vieira (2017), o atendimento, na perspectiva da integralidade, requer uma rede de atenção capaz de acolher, escutar e proteger, prevenindo revitimizações. As possibilidades do acometimento da revitimização das famílias têm implicações diretas com a violência institucional, ou seja, aquelas violências que acontecem em decorrência das dinâmicas de trabalho das próprias instituições que deveriam atuar com o acolhimento das vítimas. De acordo com o CFP (2020, p. 55) "a falta de fluxos sobre como realizar a abordagem das vítimas de violência ou testemunhas de crimes, pode resultar em informações desencontradas e revitimizantes". Nesse sentido, a revitimização pode ser evitada com estratégias de acolhimento adequadas e com uma boa gestão dos fluxos de atendimentos (no próprio equipamento e na rede).

Sobre o peso emocional envolvido nos seus trabalhos, as entrevistadas relataram que a rotina de atender famílias em situação de violência provoca "desgaste emocional”, "estresse", "sensações de impotência", dentre outros sentimentos que consideram prejudicar a saúde mental dos(as) profissionais. Segundo Carmem: "Tem casos...que deixam bastante ansiedade, bastante preocupação. Às vezes isso acontece em função do agressor, porque às vezes o agressor está solto, persegue a família...”. É importante destacar que a equipe técnica precisa ter o apoio institucional para esses casos e respaldo técnico para a garantia de boas condições de trabalho. Em decorrência das situações complexas com as quais se deparam e do impacto que este trabalho causa nos(as) trabalhadores(as), é preciso reconhecer as reais dificuldades dos profissionais na realização do atendimento e acompanhamento a famílias e indivíduos em situação de risco. Nesse sentido, é crucial que a gestão de trabalho nos equipamentos também considere a importância de momentos de integração em equipe, troca de experiências, reflexão, estudo e discussão de casos. Cabe ao órgão gestor, por sua vez, planejar e desenvolver ações de capacitação continuada e educação permanente, incluindo, inclusive, momentos com assessoria de profissional externo, além de medidas preventivas voltadas à saúde e segurança dos trabalhadores (MDS, 2011).

No que se refere ao atendimento aos autores de violência, as entrevistadas relataram não ser comum atendê-los no serviço do Paefi onde trabalham. Isso porque, quando se trata de violência sexual contra crianças e adolescentes, geralmente o autor da violência encontra-se afastado da família por meio de medidas protetivas e/ou se nega a frequentar os serviços de atenção socioassistencial. No entanto, quando o autor da violência acompanha a família no atendimento, realiza-se uma orientação geral sobre a violência praticada. Além disso, propõe-se um encaminhamento para outros serviços da rede, fluxo de trabalho que não foi aprofundado nos relatos das psicólogas. As três entrevistadas relataram percepções semelhantes em relação aos atendimentos aos autores (ou suspeitos) de violência sexual. De acordo com Helena esse atendimento teria as seguintes funções:

...orientar, falar sobre violências, sobre direitos, sobre consequências...até porque às vezes a gente não sabe de fato se isso aconteceu, se não aconteceu. Não é nosso foco estar julgando, mas estar mostrando, falando sobre direitos, o que é uma violação, o que é uma violência...(Helena). 
Segundo Romeu et al. (2014), no contexto da violência sexual, é importante que também se dê atenção ao autor da violência, principalmente em casos de violência intrafamiliar. Para os pesquisadores, nesses casos, quando o autor da violência vai com a família para o atendimento, ele, com frequência, objetiva contar sua versão da história ou negar o fato. Entender o lugar que $o$ autor da violência tem na dinâmica familiar é importante para a prevenção das reincidências da violência (Santos et al., 2014). A escuta dos autores de violência, nesses contextos, tem como finalidade o acolhimento, a orientação, a proteção e o refinamento da compreensão dos ciclos de violência; já a averiguação dos fatos cabe ao sistema de segurança e de justiça (Romeu et al., 2014). Quanto a esses procedimentos, tais aspectos ficam parcialmente evidenciados nos relatos de Camila e de Carmem:

...é bem complexo, porque a gente não pode julgar, a gente não está aqui para isso. É um atendimento que acaba sendo pesado para a equipe toda...eu acho que a pior parte do atendimento é $o$ atendimento ao agressor, é trabalhar com ele e fazer ele refletir. Normalmente eles vêm para cá e dizem que não aconteceu, que isso é besteira, que isso é boato. Então a gente fica meio em cima do muro. A gente tem que atender, tem que ser neutro, tem que escutar, tem que acolher, mas ao mesmo tempo a gente tem que proteger a criança, então assim, a gente fica no meio termo (Camila).

No geral, não é muito comum atender o agressor. Depende muito da situação. Porque às vezes o agressor está dentro da família, às vezes o agressor está fora da família, então isso varia, também se tem medida protetiva ou não (Carmem).

Os relatos de Carmem, Camila e Helena em relação aos atendimentos aos autores ou aos suspeitos de cometer violência sexual contra crianças e adolescentes pareceram-nos imprecisos em relação a suas tomadas de decisões frente aos fluxos de trabalho no equipamento e na rede. As ações, de acordo com os relatos, parecem focar no esclarecimento sobre os direitos das crianças e adolescentes e sobre a questão da violência sexual e seus efeitos psicossociais um trabalho necessário e importante que se aproxima de uma atuação em psicoeducação. $O$ fato de enfatizar a ação de esclarecimento junto ao autor (ou suspeito) de violência não implica julgamento, mas refere-se justamente ao trabalho reflexivo que pode ser realizado. De acordo com os relatos, apesar de ser pouco comum o atendimento nesses casos, quando ele acontece - seja por conta do fato consumado ou por suspeita - o foco é no esclarecimento sobre as ações violentas. No entanto, os atendimentos, que parecem se restringir à escuta e aos esclarecimentos acerca dos atos cometidos, ocorrem apenas se o autor ou suspeito comparece ao equipamento. A atuação da psicologia, nesses casos, pode ir além do atendimento "face a face" com fins de "esclarecimento" ao autor sobre seus atos. Além de dispositivos que visam superar os modelos de atendimentos individuais, como rodas de conversa e grupos reflexivos para homens autores de violência, profissionais de psicologia também podem atuar acionando a rede do SGD.

De acordo com o CFP (2020), existem diversos modelos de intervenção psicossocial em casos de violência contra crianças e adolescentes. Resumidamente, esses modelos se assentam em três perspectivas diferentes: o modelo da intervenção punitiva primária, que foca apenas nas características individuais do autor da violência e tem como objetivo puni-lo; o modelo da intervenção primária protetora da criança, que foca na criança/adolescente vítima da violência; e o modelo da intervenção terapêutica primária, que considera a singularidade dos sujeitos, dos contextos e das famílias, de modo que a intervenção seja feita no enredamento desses aspectos. Por mais que do foco atendimento psicossocial não seja a dimensão terapêutica, o CFP orienta que os atendimentos sejam pautados por esse terceiro modelo, uma vez que ele preconiza um olhar mais integral sobre as características multifacetadas do fenômeno da violência.

De modo geral, em relação aos atendimentos a crianças e adolescentes vítimas de violência sexual e suas famílias, observou-se, por parte das três entrevistadas, o empenho - apesar das dificuldades - na efetivação da gestão de trabalho na perspectiva interdisciplinar e intersetorial. De acordo com os relatos, são realizadas reuniões entre a equipe e/ou com a coordenação e a gerência (semanal, quinzenal ou mensal), a fim de debater e problematizar questões administrativas e operacionais. Além disso, busca-se criar momentos de estudos e análises de casos; de leitura de materiais, projetos e leis; de avaliação do serviço e do trabalho da equipe; e de planejamentos das ações, encaminhamentos, articulações e parcerias 
com a rede. Na percepção das psicólogas, tais reuniões são essenciais para efetivar o trabalho e atingir os objetivos propostos no serviço.

Um ponto importante em relação a uma defasagem percebida para suas atuações profissionais refere-se à escassez de treinamentos e capacitações técnicas. De acordo com o CFP (2012), é importante que haja uma capacitação especializada e continuada em relação à área de atuação. No entanto, a oferta de capacitações especializadas para a equipe atuar no serviço parece não se efetivar. De acordo com Freire e Alberto (2013), isso denota a desresponsabilização do Estado e sua falta de articulação com os atores inseridos nas Política Públicas.

A falta de capacitação e de educação continuada à equipe técnica, especificamente aos(às) psicólogos(as), dificulta que esses(as) profissionais tenham clareza acerca do que devem fazer e como devem atuar no contexto da Assistência Social. Essa não é uma realidade apenas do serviço no qual realizamos a pesquisa. De acordo com pesquisa realizada pelo CFP (2009), 31\% dos(as) psicólogos(as) indicaram deficiências, em suas formações, acerca de conteúdos, estágios e disciplinas no campo das políticas públicas. Para o CFP (2020), a atuação da psicologia nas políticas públicas demanda especificidades para a prática profissional, de modo que os referenciais teórico-metodológicos da área estejam em estreita relação com os contextos e as demandas emergentes nos territórios.

Seja no atendimento a crianças e adolescentes vítimas de violência sexual e suas famílias ou aos autores de violência, uma problemática que se coloca sobre a compreensão do trabalho da psicologia é a diferenciação entre "atendimento psicossocial" e "psicoterapia". A confusão e a dificuldade de diferenciar essas duas modalidades de práticas é recorrente na atuação de profissionais de psicologia no contexto da Assistência Social (CFP, 2020; Lima \& Schneider, 2018). Deve-se destacar que o trabalho da psicologia nos equipamentos do Suas não deve estar pautado em modelos de psicoterapia. De acordo com o CFP (2020), é comum que a(o) profissional de psicologia confunda abordagem psicossocial com psicoterapia. Porém, ainda que o atendimento psicossocial possa ter efeitos terapêuticos, a psicoterapia deve ser realizada na atenção à saúde, especialmente nos serviços de saúde mental (CFP, 2020, p. 48).

Apesar de constatarem que os profissionais de psicologia têm dificuldades em distinguir abordagem psicossocial e psicoterapia, as entrevistadas relataram perceber que se trata de práticas distintas. O relato de Carmem é elucidativo sobre essa questão:

.... g gente atende a família, a gente faz o acolhimento à família. Posteriormente, também à criança, a gente orienta de acordo com a lei, a gente orienta quais os procedimentos que essa mãe deve fazer... a gente articula com o conselho tutelar, muitas vezes uma psicoterapia também, seja através de uma UBS, seja através de clínicas-escolas, ou outro local que possa estar ofertando (Carmem).

De modo geral, percebemos que, apesar da percepção de que haveria uma "linha tênue" entre atendimento psicossocial e psicoterapia, as entrevistadas buscam construir práticas e modos de intervir alinhados às prerrogativas do trabalho da psicologia no âmbito do Suas. Nesse sentido, percebe-se na práxis um esforço metodológico que se aproxima das orientações do CFP, que propõe que, em casos de situação de violência, as intervenções devem estar pautadas em reformulações dos fazeres mais tradicionais da psicologia, de modo a "adaptar e inovar saindo da clínica tradicional para a proposição e oferecimento de atendimentos psicossociais" (CFP, 2020, p. 20).

\section{Percepções acerca da gestão de trabalho e das estratégias de intervenções psicossociais}

De acordo com as três psicólogas, os atendimentos psicossociais no Creas/Paefi iniciam-se por meio do encaminhamento da criança e/ou do adolescente para o serviço. Com frequência, os casos são encaminhados pelo Conselho Tutelar; pela Delegacia de Proteção à Criança, Adolescente, Mulher e Idoso (DPCAMI); pelo Juizado da Infância e Juventude; pelo Sistema Único de Saúde; e/ ou, eventualmente, por demanda espontânea. Quando chega ao serviço uma situação de violência sem notificação, um relatório é enviado para o Conselho Tutelar para uma triagem e investigação do caso. Além disso, a família é orientada a registrar um Boletim de Ocorrência. Helena nos contou sobre o fluxo de entrada no serviço:

...grande parte das situações a família não quer estar aqui, porque vêm encaminhadas 
por serviços, na sua maioria conselho tutelar ou DPCAMI...denúncia por parte da Unidade Básica de Saúde...raramente, de modo espontâneo. Por exemplo, violência sexual, quando chega aqui, deve-se ter um protocolo, de já ter sido feito investigação, já ter passado pelo conselho, e chegar aqui a gente trabalhar a questão da orientação e encaminhamentos necessários. Quando isso não acontece...a gente procura o Conselho Tutelar, que no nosso entendimento é quem tem obrigação, ou que seria o órgão ideal a fazer esse boletim de ocorrência, uma triagem e investigação. Porque o Paefi fazendo isso, o que pode acontecer? Se você faz um BO desse, dependendo da situação, você perde a família. Então, o nosso papel não é de investigar, é de orientar, dar suporte para a família (Helena).

Após o Creas/Paefi receber o encaminhamento, o(a) responsável pela criança ou adolescente recebe o que o serviço denomina como "acolhimento e triagem". De acordo com as psicólogas, essa modalidade de atendimento tem como objetivo identificar possíveis situações de violação de direitos, demandas e necessidades; explicar como o serviço funciona e como pode auxiliar os(as) usuários(as); e criar um vínculo com a família. De acordo o MDS (2011), esse momento irá contribuir para o início da construção do vínculo, bem como norteará as primeiras ações da equipe técnica.

Segundo as entrevistadas, durante os atendimentos (individual e familiar) a equipe técnica (psicóloga e assistente social ou psicóloga e pedagoga) realiza uma coleta e análise de dados da composição e dinâmica familiar, da percepção dos envolvidos diante da violência sexual, da rede de apoio da família, dos fatores contribuintes para a situação de violência sexual e dos danos emocionais. A partir dessas informações, traça-se um plano de atendimento elaborado de forma conjunta com a família, buscando atender as necessidades da criança e/ou adolescente e sua família. Além disso, realiza-se encaminhamentos para outros serviços no município, como creches e escolas, Unidades Básicas de Saúde, projetos no contraturno escolar, clínicas-escolas ligadas a instituições de ensino superior, entre outros. No decorrer desse processo, a equipe técnica realiza o acompanhamento do caso e, se necessário, propõe estudos de caso com os profissionais da rede. Por fim, quando a família supera a violação dos direitos, procede-se seu desligamento do serviço.

Segundo as psicólogas, as principais ações referentes os fluxos do trabalho desenvolvidas pelas equipes técnicas são: acolhida; escuta especializada ${ }^{4}$; orientação e encaminhamentos para a rede; construção de plano de atendimento; orientação familiar; atendimento psicossocial; informação, comunicação e defesa de direitos; apoio à família em sua função protetiva; articulação da rede de serviços socioassistenciais; articulação com os serviços de outras políticas públicas; articulação interinstitucional com os demais órgãos do SGD; trabalho interdisciplinar; elaboração de relatórios e/ou prontuários; produção de orientações técnicas e informações sobre o serviço. Na percepção das psicólogas, essas ações visam à superação da situação de violência, fortalecem os vínculos familiares e promovem o desenvolvimento da autonomia e a construção de projetos futuros. Segundo o CFP (2009), essas ações pretendem garantir o compromisso ético, político e multidisciplinar das práticas socioassistenciais.

Em relação às estratégias utilizadas no atendimento psicossocial a crianças e adolescentes vítimas de violência sexual, as entrevistadas relataram: acolher as demandas; orientar e trabalhar as potencialidades e a autonomia das famílias, das crianças e adolescentes; oferecer uma escuta qualificada para que se identifique as necessidades de cada caso; e estabelecer ações conjuntas com outros serviços e projetos do município, para que sejam implementadas ações mais efetivas que resultem no fortalecimento dos vínculos familiares e na superação das violências. Com os adolescentes, Camila, Carmem e Helena relataram utilizar a linguagem verbal. Já com crianças, utilizam intervenções baseadas em propostas lúdicas.

No que se refere à estratégia de prevenção, as três entrevistadas relataram uma ação realizada no dia

\footnotetext{
${ }^{4}$ Em abril de 2017 foi promulgada a Lei n. 13.431 que "Estabelece o sistema de garantia de direitos da criança e do adolescente vítima ou testemunha de violência e altera a Lei 8.069, de 13 de julho de 1990 (Estatuto da Criança e do Adolescente)". Nesta Lei, as ações propostas resumem-se a duas: a escuta especializada (acolhimento) e o depoimento especial (produção de prova). Segundo o CFP (2018), essa lei irá gerar impactos, uma vez que a preocupação com a produção de prova é destacada e o acolhimento não é priorizado. Cabe destacar que, segundo o CFP, o depoimento especial como forma de inquérito viola o direito de crianças e adolescentes, que passam a ser objeto de provas no processo penal.
} 
18 de maio (Dia Nacional de Combate ao Abuso e à Exploração Sexual de Crianças e Adolescentes) com a rede do município, que objetivou promover a capacitação dos profissionais da rede de cuidados e proteção. Helena relatou sua percepção sobre a ação:

...foi chamado representantes da rede, de escolas, os Cras, Unidades Básicas de Saúde...para capacitar profissionais da rede, como lidar quando chegar situações de violência sexual principalmente...acho que a partir desse evento, a impressão não é só minha, mas de algumas outras pessoas, que houve uma aproximação da rede no sentido de: "bah, tem quem pode nos ajudar, sabe?"(Helena).

De acordo com Camila, Helena e Carmem, há um movimento no serviço do Paefi que busca capacitar a rede do município. As entrevistadas avaliaram a ação como fundamental, no sentido de evitar, reduzir e interromper os casos de violência sexual. No entanto, identifica-se que ações de prevenção contra a violência sexual são escassas. Desse modo, de acordo com Faraj, Siqueira e Arpini (2016), é necessário maior investimento profissional, engajamento e, sobretudo, consciência de que o trabalho conjunto e articulado possibilita enfrentar o fenômeno da violência, bem como garantir e reparar os direitos de quem foi violado. Compreendemos que a promoção de novas práticas no campo das políticas públicas, aliadas ao comprometimento do poder público e do Estado, são fundamentais para a superação das fragilidades existentes na rede de atendimento e de proteção à criança e ao adolescente.

\section{Considerações finais}

Este artigo objetivou problematizar as percepções de psicólogas de um Creas/Paefi localizado na região metropolitana de Florianópolis acerca dos atendimentos psicossociais a crianças e adolescentes vítimas de violência sexual. Observou-se que as percepções das entrevistadas acerca da violência sexual intercalavam entre compreensões complexas, que levavam em consideração questões estruturais e de poder, e perspectivas genéricas e reducionistas, que culpabilizavam e/ou responsabilizavam apenas as famílias por suas situações de vulnerabilidades. Em relação aos atendimentos psicossociais no âmbito do Paefi, identificou-se a percepção de que as ações devem ser realizadas em rede, apesar das dificuldades na gestão do trabalho intersetorial.

Aponta-se que, a despeito das idiossincrasias referentes ao trabalho junto a crianças e adolescentes vítimas de violência sexual, há um esforço, por parte das trabalhadoras entrevistadas, para fazer valer o Sistema de Garantia de Direitos de Crianças e Adolescentes. As dificuldades na gestão de trabalho e na condução dos atendimentos às famílias, muitas vezes, extrapolam a alçada das profissionais. Isso porque, considerando a complexidade dos fenômenos com os quais precisam lidar, a fragilidade e a desarticulação da rede de atendimento e proteção, e a ausência e negligência do Estado na efetivação de políticas públicas e sociais, as estratégias de intervenção, muitas vezes, acabam ficando comprometidas. No entanto, no que tange ao atendimento psicossocial no Creas/Paefi no qual a pesquisa foi realizada, constatou-se que naquele equipamento cumprem-se as etapas do atendimento psicossocial, a saber: acolhimento e triagem; elaboração do plano de atendimento; encaminhamentos, acompanhamento e encerramento do atendimento. $\mathrm{O}$ atendimento psicossocial é voltado especialmente para orientação e conscientização sobre a problemática da violência. Além disso, as principais ações desenvolvidas visam à superação da situação de violência, ao fortalecimento dos vínculos familiares, à promoção do desenvolvimento da autonomia e à construção de projetos futuros.

Destaca-se que a desarticulação da rede, a falta de capacitação técnica aos(às) trabalhadores(as) do Suas e negligência do Estado são pontos que requerem atenção especial. Nesse sentido, sugerem-se ações que pressionem o poder público para se responsabilizar com a efetivação do sistema de garantia de direitos de famílias em situação de vulnerabilidade, especialmente no que diz respeito às problemáticas relacionadas à violência sexual contra crianças e adolescentes. 


\section{Referências}

Andrade, E. M., Nakamura, E., Paula, C. S. de, Nascimento, R. do, Bordin, I. A., \& Martin, D. (2011). A visão dos profissionais de saúde em relação à violência doméstica contra crianças e adolescentes: Um estudo qualitativo. Saúde e Sociedade, 20(1), 147-155. https:// doi.org/10.1590/S0104-12902011000100017

Conselho Federal de Psicologia. (2009). Serviço de Proteção Social a crianças e adolescentes vítimas de violência, abuso e exploração sexual e suas famílias: Referências para a atuação do psicólogo. https://site.cfp.org.br/ wp-content/uploads/2009/10/CREPOP_Servico_Exploracao_Sexual.pdf

Conselho Federal de Psicologia. (2018). Nota técnica n. 1/2018/GTEC/CG. http://www.crpsp.org.br/arquivos/ NOTA-TECNICA-N-1_2018_GTEC_CG.pdf

Conselho Federal de Psicologia. (2012). Referências técnicas para prática de psicólogas(os) no Centro de Referência Especializado da Assistência Social - CREAS. https://site.cfp.org.br/wp-content/uploads/2013/08/CREPOP_ CREAS_.pdf

Conselho Federal de Psicologia. (2020). Referências técnicas para a atuação de psicólogas(os) na rede de proteção às crianças e adolescentes em situação de violência sexual. https:/ / bit.ly/3ozVkmW

Decreto n. 9.603, de 10 de dezembro de 2018. (11 dez. 2018). Regulamenta a Lei no 13.431, de 4 de abril de 2017, que estabelece o sistema de garantia de direitos da criança e do adolescente vítima ou testemunha de violência. Diário Oficial da União. http://www.planalto.gov.br/ccivil_03/_ato2015-2018/2018/decreto/D9603.htm

Denzin, N. K., \& Lincoln, Y. S. (2006). Introdução: A disciplina e a prática da pesquisa qualitativa. In N. K. Denzin \& Y. S. Lincoln (Orgs.), (2006). O planejamento da pesquisa qualitativa: Teorias e abordagens (2. ed., pp. 15-41). Artmed.

Faraj, S. P., \& Siqueira, A. C. (2012). O atendimento e a rede de proteção da criança e do adolescente vítima de violência sexual na perspectiva dos profissionais do CREAS. Barbarói, 2(37), 67-87. https://online.unisc.br/seer/ index.php/barbaroi/article/view/2097/2357

Faraj, S. P., Siqueira, A. C., \& Arpini, D. M. (2016). Rede de proteção: O olhar de profissionais do sistema de garantia de direitos. Temas em Psicologia, 24(2), 727-741. Associação Brasileira de Psicologia. http://doi.org/ 10.9788/ TP2016.2-18

Freire, M. L., \& Alberto, M. de F. P. (2013). Centro de referência especializada de assistência social: Suporte organizacional para atuação do psicólogo. Cadernos de Psicologia Social do Trabalho, 16(2), 167-182. http://pepsic. bvsalud.org/pdf/cpst/v16n2/a03v16n2.pdf

Gil, A. C. (2002). Como elaborar projetos de pesquisa (4a ed.). Atlas.

Itaboraí, N. R. (2017). Mudanças nas famílias brasileiras (1976-2012): Uma perspectiva de classe e gênero (1a ed.). Garamond.

Lei n. 8.069, de 13 de julho de 1990. (16 jul. 1990). Dispõe sobre o Estatuto da Criança e do Adolescente e dá outras providências. Diário Oficial da União. http://www.planalto.gov.br/ccivil_03/LEIS/L8069.htm

Lei n. 12.435, de 06 de julho de 2011. (07 jul. 2011). Altera a Lei no 8.742, de 7 de dezembro de 1993, que dispõe sobre a organização da Assistência Social. Diário Oficial da União. http://www.planalto.gov.br/ccivil_03/_ato20112014/2011/lei/112435.htm

Lei n. 13.431, de 04 de abril de 2017. (05 abr. 2017). Estabelece o sistema de garantia de direitos da criança e do adolescente vítima ou testemunha de violência e altera a Lei no 8.069, de 13 de julho de 1990 (Estatuto da Criança e do Adolescente). Diário Oficial da União. http://www.planalto.gov.br/ccivil_03/_Ato2015-2018/2017/Lei/ L13431.htm

Lima, F. C, \& Schneider, D. R. (2018). Características da atuação do psicólogo na Proteção Social Especial em Santa Catarina. Psicologia: Ciência e Profissão, 38(2), 347-362. https://doi.org/10.1590/1982-3703001402017

Ministério do Desenvolvimento Social e Combate à Fome. (2004). Política Nacional de Assistência Social (PNAS/2014). https://www.mds.gov.br/webarquivos/publicacao/assistencia_social/Normativas/PNAS2004.pdf

Ministério do Desenvolvimento Social e Combate à Fome. (2011). Orientações técnicas: Centro de Referência Especializado de Assistência Social - CREAS. http://aplicacoes.mds.gov.br/snas/documentos/04-caderno-creasfinal-dez..pdf 
Paixão, A. C. W. da, \& Deslandes, S. F. (2010). Análise das políticas públicas de enfrentamento da violência sexual infantojuvenil. Saúde e Sociedade, 19(1), 114-126. https://doi.org/10.1590/S0104-12902010000100009

Pedersen, J. R. (2010). Abuso sexual intrafamiliar: Do silêncio ao seu enfrentamento [Dissertação de mestrado, Faculdade de Serviço Social, Pontifícia Universidade Católica do Rio Grande do Sul]. http://tede2.pucrs.br/ tede2/bitstream/tede/459/1/422452.pdf

Pereira, V., \& Guareschi, P. A. (2017). A psicologia no CRAS: Um estudo de representações sociais. Psicologia \& Sociedade, 29, e119584. https://dx.doi.org/10.1590/1807-0310/2017v29119584

Romeu, A. P. S., Elias, Â. de N. S., \& Silva, E. G. P. O. (2014). A atenção a crianças e a adolescentes vítimas de violência sexual nos Centros de Referência Especializados de Assistência Social (CREAS). In B. R. dos Santos, I. B. Gonçalves \& G. Vasconcelos (Orgs.), Escuta de crianças e adolescentes em situação de violência sexual: Aspectos teóricos e metodológicos (pp. 167-182). Universidade Católica de Brasília. http://prattein.com.br/home/images/ stories/230813/direitos_crianca_adolescente/Escuta_violncia_sexual.pdf

Santos, B. R., Ippolito, R., Magalhães, M. L. (2014). Políticas públicas, rede de proteção e os programas e serviços voltados para crianças e adolescentes em situação de violência sexual. In B. R. dos Santos, I. B. Gonçalves \& G. Vasconcelos (Orgs.), Escuta de crianças e adolescentes em situação de violência sexual: Aspectos teóricos e metodológicos (pp. 113-130). Universidade Católica de Brasília. http://prattein.com.br/home/images/stories/230813/ direitos_crianca_adolescente/Escuta_violncia_sexual.pdf

Silva, P. A., Lunardi, V. L., Ribeiro, J. P., Oliveira, A. M. N., \& Vasquez, T. C. S. (2014). Notificação da violência intrafamiliar contra crianças e adolescentes por profissionais de saúde no Brasil. Avances en Enfermería, 33(1), 142-150. https:// doi.org/ 10.15446/av.enferm.v33n1.40585

Spink, M. J. P., \& Medrado, B. (2004). Produção de sentidos no cotidiano: Uma abordagem teórico-metodológica para análise das práticas discursivas. In M. J. Spink (Org.), Práticas discursivas e produção de sentidos no cotidiano: Aproximações teóricas e metodológicas (3a ed., pp. 1-20). Cortez.

Veloso, M. M. X., Magalhães, C. M. C., \& Cabral, I. R. (2017). Identificação e notificação de violência contra crianças e adolescentes: Limites e possibilidades de atuação de profissionais de saúde. Mudanças: Psicologia da Saúde, 25(1), 1-8. https://doi.org/10.15603/2176-1019/mud.v25nlpl-8

Vieira, M. S. (2017). Em busca da integralidade no atendimento à violência sexual contra crianças e adolescentes: Reflexões a partir da realidade dos CREAS Tocantinenses. Revista Sociais e Humanas, 30(3), 55-72. https://doi. org/10.5902/2317175828948

Waiselfisz, J. J. (2012). Mapa da violência 2012: Crianças e adolescentes do Brasil. Cebela; Flacso Brasil. https:/ crianca. mppr.mp.br/arquivos/File/publi/xtras/mapaviolencia2012_criancas_e_adolescentes.pdf

Waiselfisz, J. J. (2015). Mapa da violência 2015: Homicídio de mulheres no Brasil. Flacso Brasil. http:/ /www.onumulheres. org.br/wp-content/uploads/2016/04/MapaViolencia_2015_mulheres.pdf

Werneck, A. F., Gonçalves, I. B., Vasconcelos, M. G. O. M. (2014). O essencial é invisível aos olhos: Impactos da violência sexual na subjetividade de crianças e de adolescentes. In B. R. dos Santos, I. B. Gonçalves \& G. Vasconcelos (Orgs.), Escuta de crianças e adolescentes em situação de violência sexual: Aspectos teóricos e metodológicos (pp. 69-90). Universidade Católica de Brasília. http://prattein.com.br/home/images/stories/230813/ direitos_crianca_adolescente/Escuta_violncia_sexual.pdf

\section{Daniel Kerry dos Santos}

Psicólogo (CRP 12/11122), Bacharel e Licenciado em Psicologia pela Universidade Estadual Paulista (Unesp), Assis - SP, Brasil. Especialista em Psicologia Clínica pelo Conselho Federal de Psicologia (CFP). Mestre e Doutor em Psicologia pela Universidade Federal de Santa Catarina (UFSC), Florianópolis - SC, Brasil. Membro do núcleo de pesquisa Margens - Modos de vida, Família e Relações de Gênero (UFSC). Atua como psicólogo clínico e social, como esquizoanalista em consultório particular em Florianópolis e como pesquisador independente nas áreas da Psicologia Social Crítica, Esquizoanálise, Estudos de Gênero e Sexualidades e Estudos da Subjetividade.

E-mail: dakerry@gmail.com

(1) https://orcid.org/0000-0002-5464-5010 


\section{Jessica Souza Martins}

Psicóloga (CRP 12/18280) pela Universidade do Sul de Santa Catarina (Unisul/Campus Pedra Branca), Palhoça SC, Brasil. Atua como psicóloga clínica em consultório particular em Palhoça e São José - SC, Brasil, e como pesquisadora independente na área da Psicologia Social.

E-mail: jessicadesigner@hotmail.com.br

(1) https://orcid.org/0000-0002-6906-7575

Endereço para envio de correspondência:

Rodovia Amaro Antônio Vieira, 2797, bloco C, apto.701, Itacorubi, CEP: 88034-101. Florianópolis - SC. Brasil.

Recebido 30/01/2020

Aceito 04/08/2021

Received $01 / 30 / 2020$

Approved 08/04/2021

Recibido 30/01/2020

Aceptado 04/08/2021

Como citar: Martins, J. S., \& Santos, D. K. dos. (2022). Atendimentos psicossociais a crianças e adolescentes vítimas de violência sexual: Percepções de psicólogas de um Creas/Paefi. Psicologia: Ciência e Profissão, 42, 1-18. https://doi.org/10.1590/1982-3703003233520

How to cite: Martins, J. S., \& Santos, D. K. dos. (2022). Psychosocial assistance to children and adolescents victims of sexual violence: Perceptions of psychologists from a CREAS/PAEFI. Psicologia: Ciência e Profissão, 42, 1-18. https://doi.org/10.1590/1982-3703003233520

Cómo citar: Martins, J. S., \& Santos, D. K. dos. (2022). Asistencia psicosocial a niños y adolescentes víctimas de violencia sexual: Percepciones de psicólogas de un CREAS/PAEFI. Psicologia: Ciência e Profissão, 42, 1-18. https://doi.org/10.1590/1982-3703003233520 